DOI 10.37882/2223-2982.2020.06.06

\title{
КОГНИТИВНО-ДИНАМИЧЕСКАЯ МОДЕЛЬ СИНХРОННОГО ПЕРЕВОДА
}

\section{COGNITIVE DYNAMIC MODEL OF SIMULTANEOUS INTERPRETATION \\ D. Balaganov}

Summary: In this article, the author, based on the previous analysis and review, provides his own views on the functioning of the cognitive mechanisms in dynamics (both in normal conditions and in the changed situation of the interpretation). The author has provided the cognitive dynamic model of the simultaneous interpretation. He has demonstrated the stress factors affecting the functioning of the cognitive mechanisms. The author has described the countermeasures undertaken by an interpreter to mitigate the stress load on each cognitive mechanism. The results of the research can be used by theoreticians and practitioners in the educational process to train simultaneous interpreters.

Keywords: cognitive dynamic model, simultaneous interpretation, cognitive mechanisms, cognitive system, altered state of the linguistic conscience, stress load, stress mitigation.

\author{
Балаганов Дмитрий Владимирович \\ К.филол.н., Военный университет Министерства \\ обороны Российской Федерации, Москва \\ dmitryrus@yandex.ru
}

Аннотация: В настоящей статье автором, на основе проведенного ранее анализа и обзора, приведены собственные взгляды на функционирование когнитивных механизмов в динамике (как в обычных условиях, так и при изменении ситуации перевода). Представлена когнитивно-динамическая модель синхронного перевода. Показаны стресс-факторы, влияющие на функционирование когнитивных механизмов. Описаны контрмеры, предпринимаемые переводчиком для нивелирования стрессогенной нагрузки на каждый когнитивный механизм. Результаты исследования могут быть использованы теоретиками и практиками в рамках образовательного процесса по подготовке переводчиков-синхронистов.

Ключевые слова: когнитивно-динамическая модель, синхронный перевод, когнитивные механизмы, когнитивная система, изменение состояния языкового сознания, стрессогенная нагрузка, нивелирование стресса.

вода, рассмотрев функционирование соответствующих когнитивных механизмов. В этом заключается новизна настоящей статьи. Наше представление как когнитивного механизма, в общем, так и когнитивных механизмов синхронного перевода, в частности, подробно описано в одной из наших статей [1].

Целью настоящей работы является представить когнитивно-динамическую модель синхронного перевода. Для ее достижения планируем выполнить следующие задачи:

- пояснить отличие когнитивно-динамической модели от других моделей данного вида перевода;

- описать структуру модели и функционирование ее отдельных элементов, как в обычных условиях, так и в условиях увеличения стрессогенной нагрузки;

- указать на способы преодоления последствий стресса.

Основными методами исследования были анализ имеющихся моделей синхронного перевода, а также психолингвистический и психофизиологический эксперимент, проведенный нами ранее (подробнее см. [2]).

\section{СУШНОСТЬ КОГНИТИВНО-АИНАМИЧЕСКОЙ

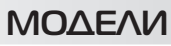

Проводя сравнение с уже имеющимися моделями 
синхронного перевода, необходимо отметить следующее. В моделях Д. Гервера [11, 12] и Б. Мозер [16] основное внимание уделяется процессу обработки информации. Прогностическая модель Г.В. Чернова [9] выделяет в качестве основного элемента вероятностное прогнозирование. Нельзя не согласиться с тем, что оно играет одну из важных ролей в процессе синхронного перевода. Однако на профессиональную надежность переводчика оказывают влияние и другие элементы. Деятельностная модель А.Ф. Ширяева [10] дает довольно полное описание процесса синхронного перевода. При этом в ней не учитываются изменения в работе переводчика при увеличении стресса. Модель усилий Д. Жиля [13] изначально была посвящена процессу подготовки переводчиков. В ней описаны основные усилия (девербализация исходного сообщения, его переформулирование и вербализация на языке перевода), которые предпринимаются переводчиком-синхронистом. Любые опущения и искажения интерпретируется в ней как превышения потенциала переводчика. Несмотря на определенную когнитивную составляющую этой модели, в ней не дается полного представления обо всех процессах, протекающих в синхронном переводе. Остальные модели так или иначе являются следствием указанных выше моделей. В отличие от них предлагаемая нами когнитивно-динамическая модель синхронного перевода дает описание когнитивных механизмов и их динамику в зависимости от изменений в ситуации перевода, а также представление о тех способах, которые задействуются переводчиком для преодоления последствий роста стресса.

Как любая модель процесса перевода, когнитивно-динамическая модель синхронного перевода представляет собой схематическое отображение динамики тех когнитивных механизмов, которые функционируют в ходе осуществления переводчиком своих профессиональных обязанностей. Учитывая тот дефицит времени, который испытывает синхронный переводчик, следует понимать, что эти когнитивные механизмы задействуются переводчиком не последовательно, а практически параллельно друг другу, тем самым увеличивая когнитивную нагрузку.

Мы исходим из положения о том, что в процессе синхронного перевода с ростом стресса может, в той или иной степени, происходить изменение состояния языкового сознания переводчика (подробнее см. [2]). В зависимости от уровня подготовленности переводчика, как в лингвистическом, так и в психологическом плане, он адаптируется к новой измененной ситуации перевода и применяет те или иные приемы для преодоления последствий увеличенного стресса. Это позволяет ему не допустить потери переводимой информации. Поэтому профессиональная надежность переводчика-синхрониста напрямую зависит от того, насколько он способен нивелировать последствия дополнительной стрессогенной нагрузки.

\section{СТРУКTУРА MOАЕАИ}

Предлагаемая нами когнитивно-динамическая модель (схема 1) синхронного перевода представляет собой когнитивные механизмы, задействуемые переводчиком и находящиеся в определенной взаимосвязи друг с другом, лингвистические и экстралингвистические стресс-факторы, которые оказывают определенное вли-

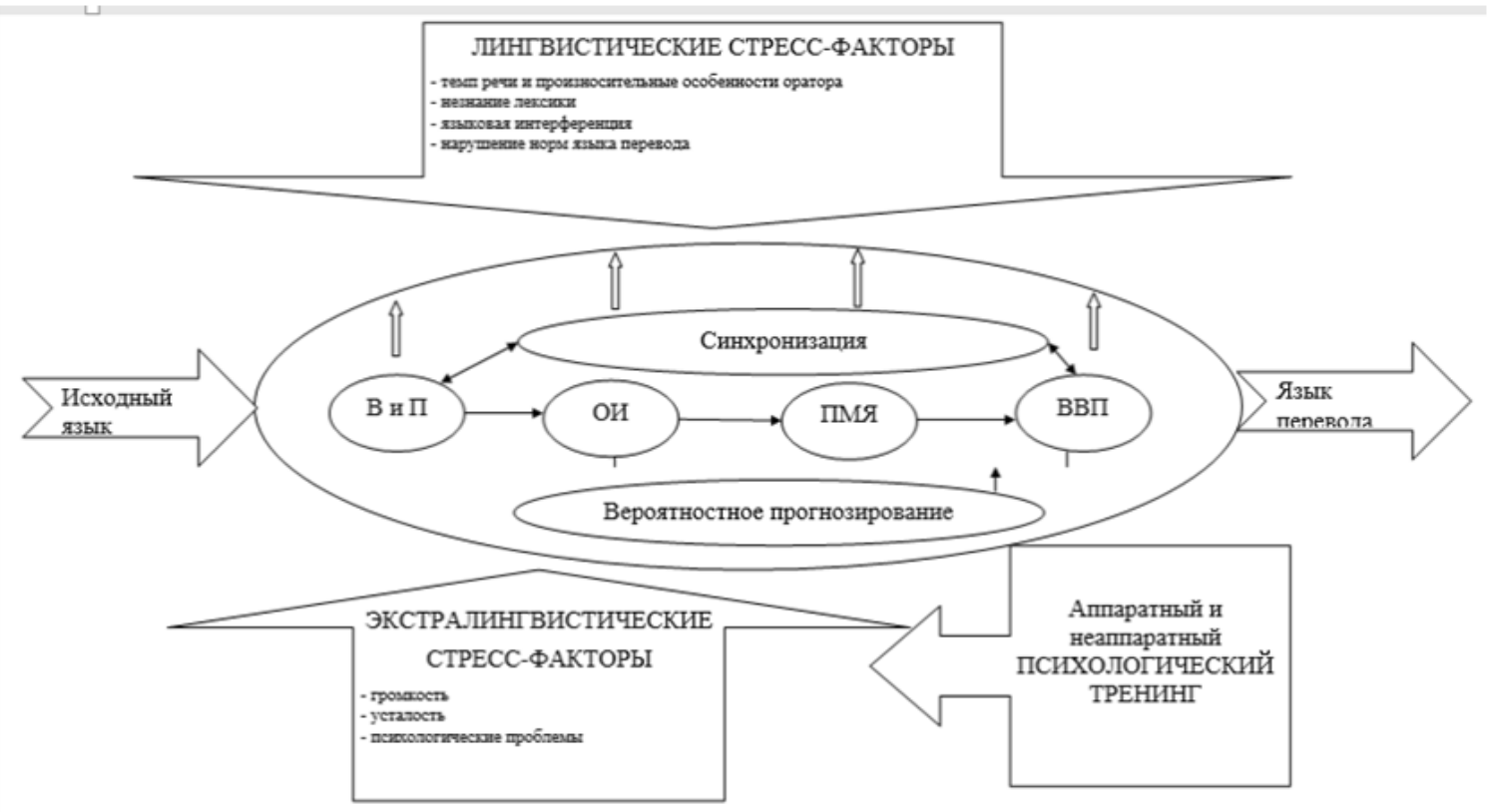

Рис .1. Когнитивно-динамическая модель. Cognitive dynamic model 
яние на эти когнитивные механизмы, а также ответную неспецифическую реакцию переводчика-синхрониста, направленную на адаптацию или компенсацию измененного состояния языкового сознания.

При поступлении отрывка речи оратора переводчик задействует когнитивный механизм восприятия и понимания. На данном этапе происходит корреляция отдельных фонем с имеющимися в долговременной памяти переводчика фонемными наборами и соединение их в отдельные словоформы. После этого переводчик вычленяет значение, которым, по его мнению, обладает конкретное слово в речи оратора, а также определяет место данного слова в высказывании на исходном языке. База данных различных значений слов также находится в долговременной памяти переводчика-синхрониста. Для оперативного доступа к ней и извлечения необходимой информации существуют определенные триггеры, позволяющие переводчику максимально точно идентифицировать услышанный набор звуков с тем или иным словом.

При увеличении темпа речи оратора, а также при наличии у него определенных произносительных особенностей (диалектическая речь, нарушение общепринятых произносительных норм, дефекты речи и другие) синхронному переводчику приходится прибегать к различным стратегиям синхронного перевода (подробнее см. $[5,6])$. К числу основных, на наш взгляд, можно отнести опущение, компенсацию, компрессию.

После идентификации конкретной группы слов переводчик-синхронист приступает к обработке информации. На данном этапе на уровне слов и словосочетаний происходит уточнение значения отдельных слов в зависимости от их сочетаемости в конкретном отрезке речи оратора. На уровне предложения переводчик уточняет места отдельных слов и, соответственно, уясняет локальную интенцию автора исходного сообщения, который для этого использовал определенный порядок и набор слов. На уровне сверхфразовых единств синхронист уточняет и накапливает информацию относительно общего замысла оратора, выражаемого в его речи. Тем самым мы наблюдаем то, что Г.В. Чернов называет кумулятивно-динамическим анализом [9].

Основными лингвистическими стресс-факторами для данного когнитивного механизма являются терминологическая лексика, используемые автором исходного сообщения аббревиатуры, фразеологические единицы, каламбуры.

К числу контрмер, которые помогают переводчику преодолевать дополнительную стрессогенную нагрузку такого рода, помимо тех или иных стратегий, отнесем постоянную актуализацию своих знаний относительно тер- минологии конкретной сферы человеческой деятельности, расширение собственных фоновых знаний, а также пополнение базы данных переводческих соответствий устойчивых выражений, хранящихся в долговременной памяти.

При восприятии первого отрезка исходного сообщения у переводчика-синхрониста активизировалась языковая система исходного языка. После обработки поступившей информации активизируется и языковая система языка перевода, и впредь до окончания процесса синхронного перевода обе эти языковые системы остаются в активном состоянии. В этот момент мы наблюдаем задействование механизма переключения между языками. Данный механизм обеспечивает постоянное сканирование обеих систем на предмет соответствий единиц языка перевода единицам исходного языка. Поддержание обеих систем в активном состоянии требует от переводчика-синхрониста значительных когнитивных усилий.

Наибольшей стрессогенностью для когнитивного механизма переключения между языками обладает межъязыковая интерференция. Для нивелирования ее влияния переводчик должен уметь подавлять интерферирующие соответствия и активизировать те соответствия, которые наилучшим образом удовлетворяют нормам языка перевода. Также в данном случае переводчик часто использует прием самокоррекции.

После задействования системы языка перевода синхронный переводчик осуществляет выбор варианта перевода обработанного отрезка речи оратора. На данном этапе происходит проверка предполагаемого варианта на предмет соответствия смыслу исходного сообщения и нормам языка перевода. Здесь необходимо отметить тот факт, что переводчику приходиться постоянно сверяться с той терминологической базой, которая соответствует той или иной тематике выступления. Помимо этого синхронист, постоянно отслеживая настроение и намерения автора сообщения, подбирать соответствующие элементы в языке перевода.

При восприятии первого отрезка исходного сообщения у переводчика-синхрониста активизировалась языковая система исходного языка. После обработки поступившей информации активизируется и языковая система языка перевода, и впредь до окончания процесса синхронного перевода обе эти языковые системы остаются в активном состоянии. В этот момент мы наблюдаем задействование механизма переключения между языками. Данный механизм обеспечивает постоянное сканирование обеих систем на предмет соответствий единиц языка перевода единицам исходного языка. Поддержание обеих систем в активном состоянии требует от переводчикасинхрониста значительных когнитивных усилий. 
Наибольшей стрессогенностью для когнитивного механизма переключения между языками обладает межъязыковая интерференция. Для нивелирования ее влияния переводчик должен уметь подавлять интерферирующие соответствия и активизировать те соответствия, которые наилучшим образом удовлетворяют нормам языка перевода. Также в данном случае переводчик часто использует прием самокоррекции.

После задействования системы языка перевода синхронный переводчик осуществляет выбор варианта перевода обработанного отрезка речи оратора. На данном этапе происходит проверка предполагаемого варианта на предмет соответствия смыслу исходного сообщения и нормам языка перевода. Здесь необходимо отметить тот факт, что переводчику приходиться постоянно сверяться с той терминологической базой, которая соответствует той или иной тематике выступления. Помимо этого синхронист, постоянно отслеживая настроение и намерения автора сообщения, подбирать соответствующие элементы в языке перевода.

Одним из факторов, обладающих наибольшей стрессогенностью для механизма выбора варианта перевода, является структурно-семантический разрыв между исходным языком и языком перевода. Другими словами, структура высказывания и заложенный в него смысл автором исходного сообщения не всегда совпадают с аналогичными конструкциями на языке перевода.

Для нивелирования негативного влияния стрессиндуцированных ошибок при выборе варианта перевода переводчик-синхронист должен постоянно совершенствовать свои языковые знания, расширять собственный «большой контекст», а также лучше ориентироваться в той терминологии, по тематике которой ему предстоит осуществлять синхронный перевод. При этом необходимо активнее задействовать прием самокоррекции.

Выше были нами упомянуты те когнитивные механизмы, которые располагаются в нашей модели в той или иной степени последовательно. Далее мы опишем два механизма, которые соединяют работу всех механизмов воедино.

Первым из двух таких когнитивных механизмов является вероятностное прогнозирование. Собственно механизм вероятностного прогнозирования действует следующим образом. После обработки поступающего отрезка речи оратора переводчик-синхронист, активизировав систему языка перевода, еще до окончания вербализации всего отрывка выдвигает предположение относительно его завершения. При этом он основывается на лингвистическом контексте, исходя из правил построения предложений исходного языка (лингвистическое прогнозирование), и/или отталкивается от «большого контекста», знаниями о котором обладает переводчик (экстралингвистическое прогнозирование). Сразу после этого предположения синхронист осуществляет поиск вариантов перевода и начинает вербализацию на языке перевода. Иногда, по мере развертывания высказывания на исходном языке, переводчик делает корректировку собственного варианта перевода, используя при этом прием самокоррекции или компенсации) (помимо прочего, см. [8]).

При росте стрессогенной нагрузки способность переводчика-синхрониста к вероятностному прогнозированию может довольно существенно снизиться. При этом повышается возможность перехода переводчика к более буквальному переводу, потере информации, незавершенности предложений. Все это свидетельствует об изменении состояния его языкового сознания. Во избежание таких ситуаций синхронный переводчик должен заранее готовить себя к различным непредвиденным ситуациям перевода, как в языковом, так и психологическом плане.

Еще одним когнитивным механизмом, который обеспечивает функционирование всей когнитивной системы синхронного перевода, является механизм синхронизации. Данный механизм позволяет осуществлять переводчику две основные функции: слушание на исходном языке и говорение на языке перевода. При этом переводчик-синхронист постоянно перемещает свое внимание с оратора на собственное говорение. Такой маневр вниманием зависит от места приложения основных усилий. Обычно при переводе с иностранного языка на родной центр внимания переводчика смещен в сторону оратора, поскольку синхронисту важнее правильно понять выступающего. После этого переводчику уже нет необходимости уделять существенное внимание при вербализации собственного варианта перевода на родном для него языке. При переводе с родного языка на иностранный, как правило, центр внимания переводчика смещается в сторону вербализации на иностранном языке. Это необходимо делать для самоконтроля за правильностью употребления норм языка перевода.

В результате негативного влияния стресса именно внимание переводчика подвергается существенной деградации. Достаточно всего несколько секунд невнимательного слушания оратора, чтобы переводчик-синхронист столкнулся с довольно серьезными проблемами в функционировании всех остальных когнитивных механизмов. Для недопущения такой ситуации синхронный переводчик должен уметь мгновенно расслабляться на несколько секунд для восстановления собственного внимания.

В целом, для преодоления негативных последствий 
стрессогенной нагрузки (помимо прочего см. [14]) переводчику-синхронисту необходимо следующее:

- совершенствовать собственные знания языка и терминологии;

- увеличивать объем фоновых знаний;

- уметь применять разнообразные приемы и стратегии перевода;

- ориентироваться в произносительных особенностях тех ораторов, которых предстоит переводить;

- обладать способностью к самокоррекции;

- повышать собственную психологическую готовность к непредвиденным изменениям в ситуации перевода.

\section{выво $\triangle ы$}

В результате проведенного исследования мы пришли к следующим выводам:

1. Когнитивно-динамическая модель синхронного перевода, в отличие от других моделей данного вида перевода, описывает функционирование когнитивных механизмов, что делается впервые.

2. Предлагаемая нами модель показывает работу когнитивной системы синхронного перевода как в обычных условиях, так и в условиях стресса. При этом отмечается объединяющая роль когнитивных механизмов вероятностного прогнозирования и синхронизации в обеспечении всей синхронно-переводческой деятельности.

3. Переводчик-синхронист в целях нивелирования негативных последствий стрессогенной нагрузки, вызванных различными факторами, должен постоянно совершенствовать свои лингвистические и экстралингвистические навыки, к числу которых относятся, помимо прочего, знание лингвистического и широкого контекста, психологическая готовность к непредвиденному развертыванию ситуации перевода.

\section{ЗАКАЮЧЕНИЕ}

Представленная нами когнитивно-динамическая модель синхронного перевода является результатом наших теоретических и эмпирических исследований. Она также учитывает собственный практический опыт синхронного перевода на различном уровне, как в России, так и за рубежом.

Являясь, по сути, одним из центральных элементов выдвигаемой нами когнитивно-динамической концепции синхронного перевода, работа над которой в настоящей момент продолжается, модель позволяет взглянуть на процесс синхронного перевода с точки зрения функционирования когнитивных механизмов и более полно понять те процессы, которые задействуются переводчиком-синхронистом.

Результаты нашего исследования могут быть использованы как для дальнейших теоретических изысканий в области процессуальных аспектов синхронного перевода, так и учтены при организации образовательного процесса подготовки синхронно-переводческих кадров.

\section{ЛИТЕРАТУРА}

1. Балаганов Д.В., Давыдова Т.Ю. Когнитивные механизмы в синхронном переводе // Вестник Нижегородского государственного лингвистического университета им. Н.А. Добролюбова. 2019. № 47. С. 19-32.

2. Балаганов Д.В. Влияние стресса на деятельность переводчика-синхрониста // Филологические науки. Вопросы теории и практики. №12 (90). Ч.1. - М.: Грамота, 2018. С.74-79.

3. Балаганов Д.В. Подходы к моделированию синхронного перевода // «Функциональные аспекты межкультурной коммуникации и проблемы перевода»: сборник статей I международной научной междисциплинарной конференции. Москва, 20-21 ноября 2014 г. / науч. ред. Н.Л. Соколова. - М.: РУДН, 2014. C.111-126.

4. Бейсембаева Ж.А., Сарманова Ж.С. Моделирование процесса синхронного перевода: традиционные и современные подходы // Актуальные вопросы модернизации российского образования. Материалы Международного электронного симпозиума. Махачкала, 2015. С.55-62.

5. Ганеева Э.Р. Особенности применения стратегии компрессии в синхронном переводе с русского языка на английский язык // Языковые единицы в свете современных научных парадигм (Материалы III Всероссийской научно-практической конференции с международным участием). Уфа: БашГУ, 2017. C.201-206.

6. Илюхин В.М. Стратегии в синхронном переводе (на материале англо-русской и русско-английской комбинаций перевода): дис. на соиск. учен. степ. к.филол.н. 10.02.20. - М., 2001. 206 с.

7. Каразия А.А. К вопросу создания модели синхронного перевода // Гуманитарные, социально-экономические и общественные науки, Т.3. №11. Краснодар: Наука и образование, 2015. С.219-221.

8. Прудникова В.А., Балабин В.В., Сидорова Н.А. Особенности функционирования речевой компрессии и вероятностного прогнозирования В синхронном переводе общественно-политических текстов (с русского языка на английский) // Сборник материалов III Всероссийской научно-практической конференции магистрантов. М.: РУСАЙНС, 2018. С.46-53.

9. Чернов Г.В. Теория и практика синхронного перевода. - М.: Международные отношения, 1978. 208 с. 
10. Ширяев А.Ф. Синхронный перевод. Деятельность синхронного переводчика и методика преподавания синхронного перевода. - М.: Воениздат, 1979. 183 с.

11. Gerver D. 1975. A Psychological Approach to Simultaneous Interpretation. Meta, vol.20, No.2. P.119-173.

12. Gerver D. 1976. Empirical Studies of Simultaneous Interpretation: A Review and a Model // Translation. Application and Research. New York: Gardner Press, 1976. P.165-207.

13. Gile D. 1995. Basic concepts and models for interpreter and translator training. Amsterdam: John Benjamins. $274 \mathrm{p}$.

14. Korpal P. 2016. Interpreting as a stressful activity: physiological measures of stress in simultaneous interpreting. In: Katarzyna Dziubalska-Kolaczyk, Bogusława Whyatt, Language processing in translation. P. 297-316.

15. Mizuno A. 2005. Process Model for Simultaneous Interpreting and Working Memory. Meta. Volume 50, number 2.P.739-752.

16. Moser B. 1978. Simultaneous Interpretation: a Hypothetical Model and its Practical Application // Language Interpretation and Communication. New York and London: Plenum Press. P.353-368.

๑ Балаганов Дмитрий Владимирович (dmitryrus@yandex.ru)

Журнал «Современная наука: актуальные проблемы теории и практики»

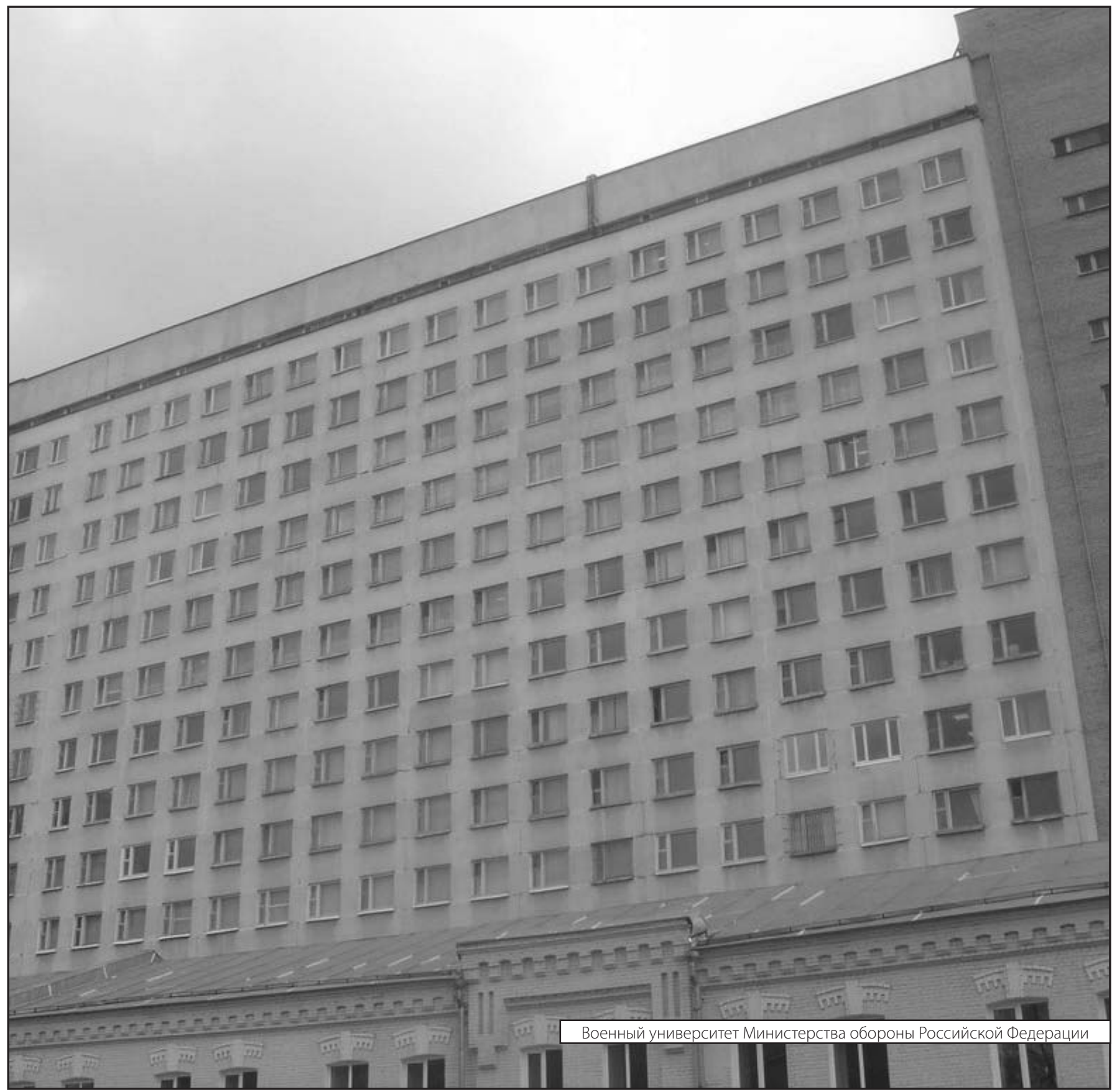

